\title{
Strategi Perbaikan Makanan Khas Bogor
}

\author{
Improvement Strategy for Bogor Indigenous Food \\ Imas Arti Suciani, Ervina Mela*, Gunawan Wijonarko
}

\begin{abstract}
${ }^{1}$ Program Studi Teknologi Pangan, Jurusan Teknologi Pertanian, Fakultas Pertanian, Universitas Jenderal Soedirman, Jl. Dr. Soeparno Karang Wangkal, Purwokerto 53121, Indonesia

${ }^{*}$ Penulis korespondensi: Ervina Mela, Email: ervina.mela@unsoed.ac.id
\end{abstract}

Tanggal submisi: 22 April 2019; Tanggal revisi 25 Mei 2020, 3 Juni 2020: Tanggal penerimaan: 5 Juni 2020

\begin{abstract}
ABSTRAK
Kota Bogor merupakan salah satu kota tujuan wisata di Indonesia. Salah satu daya tarik dari kota ini adalah makanan khas daerah tersebut. Namun demikian, hanya beberapa makanan yang dikenal secara luas. Perlu adanya identifikasi jenis makanan khas Bogor dan strategi perbaikan terhadap makanan khas Bogor yang sangat tidak populer, sehingga makanan khas ini tidak punah. Tujuan dari penelitian ini adalah mengidentifikasi makanan khas Bogor; mengetahui tingkat popularitas makanan khas Bogor; dan mendapatkan strategi perbaikan untuk makanan khas Bogor yang sangat tidak populer. Metode penelitian berupa survey, wawancara pakar, dan kuesioner. Analisis data dilakukan dengan Importance Performance Analysis (IPA). Hasil penelitian menunjukkan terdapat 12 makanan khas Bogor yaitu, Soto Mie, Soto Kuning, Laksa, Asinan, Doclang, Cungkring, Es Pala, Lapis Talas, Talas Kukus, Roti Unyil, Makaroni Panggang, dan Tauge Goreng. Makanan yang memiliki tingkat popularitas paling rendah (sangat tidak populer) yaitu Cungkring. Berdasarkan analisis tingkat kepuasan dan kepentingan dengan IPA terdapat 4 atribut Cungkring yang perlu diperbaiki. Strategi perbaikan meliputi perbaikan pada warna bumbu, warna kikil, kemasan, dan kecepatan penyajian.
\end{abstract}

Kata kunci: Bogor; strategi perbaikan; makanan khas

\begin{abstract}
Bogor constitute one of the tourist destination city in Indonesia, meanwhile, one of the attractions of this city is the indigenous food. However, only a few foods are widely known, therefore, it is necessary to identify the types of Bogor indigenous foods and strategies to improve these foods which are very unpopular to avoid extinction. This study aims to identify Bogor indigenous foods, level of popularity as well as improvement strategy. The methods used include survey, experts interview, and questionnaires while data analysis was performed using Importance Performance Analysis (IPA). Moreover, the results showed that there were 12 Bogor indigenous foods namely, Soto Mie, Soto Kuning, Laksa, Asinan, Doclang, Cungkring, Es Pala, Lapis Talas, Talas Kukus, Roti Unyil, Makaroni Panggang, and Tauge Goreng while the food with the lowest popularity level (very unpopular) is Cungkring. After analyzing the level of satisfaction and importance with IPA, there are 4 attributes of Cungkring that needs to be improved. Improvement strategies include improving spice color, gravel color, packaging and serving speed.
\end{abstract}

Keywords: Bogor; improvement strategy; indegenous food 


\section{PENDAHULUAN}

Bogor merupakan salah satu kota tujuan wisata yang sering dikunjungi oleh wisatawan. Kedekatannya dengan Kota Jakarta dan kabupaten atau kota lain di Jawa Barat menjadikan Kota Bogor sebagai salah satu tujuan wisata nasional (Mulyana, 2012). Dinas Pariwisata dan Kebudayaan Bogor, mencatat terjadi peningkatan rata-rata jumlah wisatawan ke Bogor sebesar 11,85\% setiap tahun (Kominfo, 2017).

Tingginya jumlah wisatawan yang datang ke Bogor merupakan peluang yang positif bagi pertumbuhan wisata kuliner khas Bogor, karena ketika wisatawan mengunjungi suatu daerah, maka mereka tidak hanya menikmati tempat-tempat wisata, namun juga antusias dalam menikmati beragam jenis makanan khas di daerah tersebut (Nurwitasari, 2015). Keaslian dan keunikan makanan khas suatu daerah telah menjadi salah satu daya tarik bagi wisatawan (Sari, 2017).

Bogor menjadi tempat favorit setelah Bandung untuk berwisata kuliner. Makanan khas Bogor seperti Roti Unyil, Doclang, Tauge Goreng, Laksa, Soto Kuning, Soto Mie, Lapis Bogor menjadi incaran wisatawan yang berkunjung. Toko Lapis Bogor Sangkuriang dikunjungi oleh 1000-1500 pengunjung per harinya. Adapun laksa Cihideung, dikunjungi rata-rata 150 orang perhari pada hari kerja dan 300 orang pada akhir pekan. Laksa Cihideung yang didirikan tahun 1963 ini tetap bertahan hingga sekarang, dan kini dijalankan oleh generasi keduanya (Sari, 2017). Selain makanan-makanan khas tersebut, sebenarnya Bogor masih memiliki beberapa makanan khas lainnya yang belum banyak diketahui oleh wisatawan.

Perlu ada upaya untuk mempopulerkan makanan khas Bogor dalam rangka memperkaya variasi menu yang dapat dinikmati oleh para wisatawan. Semakin beragamnya makanan khas yang dapat dinikmati wisatawan akan meningkatkan daya tarik wisata dan meningkatkan jumlah wisatawan yang pada akhirnya menjadi stimulasi bagi pertumbuhan sektor lainnya (Sari, 2017). Lebih dari itu upaya mempopulerkan makanan khas merupakan salah satu cara untuk melestarikan budaya bangsa khususnya dalam bidang kuliner, agar tidak hilang dan tergantikan oleh makanan-makanan dari luar negeri yang dengan gencar berdatangan dan semakin digemari oleh masyarakat Indonesia. Makananmakanan khas dari suatu daerah di Indonesia sudah sepantasnya mendapat perhatian dan penerimaan dari bangsa Indonesia sendiri.

Sehubungan dengan masih adanya beberapa makanan khas Bogor yang belum banyak diketahui oleh wisatawan bahkan oleh warga Bogor sendiri, perlu penelitian untuk mengidentifikasi makananmakanan khas apa saja yang ada di Bogor. Selain itu perlu pula diketahui tingkat popularitas makananmakanan khas tersebut di kalangan masyarakat khususnya wisatawan serta perlu dirumuskan strategi pengembangan terhadap makanan khas yang paling tidak populer karena makanan khas inilah yang paling berpotensi untuk punah. Adanya strategi perbaikan diharapkan dapat meningkatkan kualitas dari makanan tersebut sehingga dapat lebih diterima bahkan pada akhirnya dapat digemari oleh konsumen. Penerimaan yang baik dari konsumen terhadap makanan khas ini diharapkan dapat membuat usaha makanan khas yang pada umumnya dijalankan oleh UMKM ini meningkat pendapatannya. Lebih jauh diharapkan dapat membuka kesempatan kerja, mengurangi pengangguran, dan mengurangi tingkat kemiskinan.

Beberapa penelitian mengenai makanan khas Bogor tercatat telah dilakukan, misalnya oleh Sanny (2015) yang mengkaji strategi pengembangan bisnis bagi penjual Toge Goreng di Kota Bogor. Selain itu Sari (2017) telah melakukan penelitian mengenai Laksa Cihideung sebagai makanan unik dan asli dari Kota Bogor. Dalam bidang wisata kuliner di kota Bogor, Gunawan (2016) melakukan kajian untuk mengetahui sebaran wisata kuliner di Bogor beserta potensi dan permasalahan yang dihadapi oleh industri kuliner di Bogor. Penelitian lainnya mengenai penggunaan teknologi informasi untuk memetakan lokasi wisata tempat kuliner di Bogor telah pula dilakukan oleh Mutaqin dkk. (2015), dan Rusdiana (2016). Namun dari semua penelitian tersebut belum ditemukan penelitian yang secara khusus membahas mengenai identifikasi makanan-makanan khas Bogor dan strategi pengembangannya. Tujuan dari penelitian ini adalah untuk mengidentifikasi makanan khas Bogor, menentukan tingkat popularitas makanan khas Bogor, dan mendapatkan strategi perbaikan yang diprioritaskan untuk makanan khas Bogor yang sangat tidak populer.

\section{METODE PENELITIAN}

\section{Tempat dan Waktu Penelitian}

Penelitian dilakukan di Kota Bogor, Jawa Barat selama selama 3 bulan, dari Oktober 2018 sampai Januari 2019.

\section{Tahapan Penelitian}

Penelitian ini dilakukan melalui beberapa tahapan antara lain: (1) identifikasi makanan khas Bogor; (2) penentuan tingkat popularitas makanan khas Bogor; dan (3) upaya perbaikan terhadap makanan khas Bogor yang diprioritaskan. Pada tahapan pertama dilakukan untuk mengetahui berbagai jenis makanan khas Bogor. Metode yang dilakukan yaitu, wawancara 
pakar dan survey. Pada tahapan kedua, penentuan tingkat popularitas dianalisis melalui kuesioner tertutup yang berisi pertanyaan mengenai pengalaman responden pernah atau tidak pernah mengkonsumsi makanan khas Bogor. Pemilihan responden dilakukan berdasarkan metode Accidental Sampling. Responden pada penelitian ini yaitu wisatawan baik pria maupun wanita berusia 17-60 tahun, yang pada saat penelitian berlangsung sedang mengonsumsi makanan khas Bogor di pusat kuliner di Kota Bogor (sekitar Jalan Suryakencana). Kriteria lainnya adalah konsumen setidaknya pernah mengonsumsi dua jenis makanan khas Bogor. Penentuan kriteria ini menjadi pertimbangan dengan asumsi bahwa apabila telah mengonsumsi 2 jenis makanan khas, maka konsumen sudah memiliki pengalaman dan pengetahuan mengenai makanan khas Bogor. Adapun jumlah responden, ditentukan sebanyak 100 orang berdasarkan rumus Lemeshow (Levy dan Lemeshow, 2013). Hal ini karena tidak diketahui jumlah pasti populasi dari konsumen makanan khas Bogor sehingga jumlah sampel minimal yang diambil yaitu seperti pada Persamaan 1.

$n=\frac{Z^{2} \times \mathrm{P}(1-\mathrm{P})}{d^{2}}=\frac{1,96^{2}(0,25)}{0,5^{2}}=96,04$

Dimana $\mathrm{n}=$ jumlah sampel minimal yang dibutuhkan, $Z$ = nilai $Z$ berdasarkan $\mathrm{a}, \mathrm{P}=$ proporsi populasi yang tersedia, dan $\mathrm{d}=$ presisi/derajat akurasi

Pada penelitian ini responden ditanya pengalamannya dalam mengonsumi makanan khas Bogor. Jawaban yang tersedia terbagi atas dua alternatif yakni : "Pernah" atau "Tidak Pernah". Jawaban kemudian diberi nilai sebagai berikut: Pernah $=1$ atau Tidak Pernah $=0$ (Sugiyono, 2013). Tingkat popularitas masing-masing makanan ditentukan dari jawaban responden atas pertanyaan ini. Selanjutnya jenis makanan khas Bogor dikelompokkan popularitasnya menjadi 5 kelas menurut metode interval teratur berdasarkan modifikasi dari Knotts dkk. (2009). Interval diperoleh dari pengurangan data terbesar dengan data terkecil kemudian dibagi jumlah kelas yang akan digunakan (Persamaan 2).

Interval $=\frac{\max -\min }{\text { Jumlah kelas }}$

Pada tahapan ketiga, dilakukan dengan cara menyebarkan kuesioner mengenai kepuasan dan kepentingan konsumen terhadap makanan Bogor yang paling tidak populer. Jumlah responden ditentukan 100 orang berdasarkan rumus Lemeshow (Levy dan Lemeshow, 2013) dan melalui metode Accidental
Sampling (Sugiyono, 2013). Responden adalah konsumen yang berada di tempat penjualan makanan khas Bogor yang paling tidak populer, dengan ketentuan setidaknya pernah sekali mengonsumsi makanan khas tersebut. Konsumen diminta untuk menilai kepuasan dan kepentingan beberapa atribut makanan khas tersebut (misalnya organoleptik, penyajian, lokasi dan lain-lain). Penilaian dilakukan berdasarkan skala 1-5 mengacu pada Sunyoto (2014) antara lain: Sangat Puas/Sangat Penting (nilai $=5$ ), Puas/Penting (nilai $=4$ ), Netral (nilai = 3), Tidak Puas/Penting (nilai $=2$ ), dan Sangat Tidak Puas/Penting (nilai $=1$ ).

Total penilaian tingkat kepuasan $(X)$ dan tingkat kepentingan ( $\mathrm{Y}$ ) dihitung dengan cara menjumlahkan skor penilaian yang diberikan kemudian dibagi jumlah responden (Sunyoto, 2014). Langkah selanjutnya adalah menentukan titik potong yaitu berdasarkan nilai $\left(\overline{\bar{x}}_{i}\right)$ yang tegak lurus pada sumbu $\mathrm{x}$, dan nilai $\left(\overline{\bar{y}}_{i}\right)$ yang tegak lurus pada sumbu $\mathrm{y}$. Setelah itu dilakukan Importance Performance Analysis dengan cara memplotkan nilai-nilai tersebut ke dalam diagram kartesius yang terbagi ke dalam 4 kuadran (kuadran I, II, III, dan IV) (Melfa dan Duwi, 2013). Atribut yang berada pada kuadran I merupakan atribut dengan tingkat kepentingan yang tinggi (sumbu y sebelah atas) namun tingkat kepuasan yang rendah (sumbu x sebelah kiri). Atribut-atribut inilah yang menjadi prioritas untuk diperbaiki dan dirumuskan strategi perbaikannya.

\section{HASIL DAN PEMBAHASAN}

\section{Makanan Khas Bogor}

Berdasarkan hasil wawancara dan survey, dapat diidentifikasi 12 makanan khas Bogor, yaitu Soto Mie, Soto Kuning, Laksa, Asinan, Doclang, Cungkring, Es Pala, Lapis Talas, Talas Kukus, Roti Unyil, Makaroni Panggang, dan Tauge Goreng.

\section{Popularitas Makanan Khas Bogor}

Hasil kuesioner menunjukkan pengalaman responden yang beragam dalam mengonsumsi makanan khas Bogor. Pengalaman responden dalam mengonsumsi makanan khas Bogor dapat dilihat pada Tabel 1.

Informasi mengenai pengalaman responden dalam mengonsumsi makanan khas Bogor ini, menjadi dasar pengelompokan popularitas dari 12 produk tersebut. Pengelompokan dilakukan untuk membedakan tingkat popularitas makanan khas Bogor ke dalam 5 kelas berdasarkan interval (Persamaan 3).

Interval $=\frac{\max -\min }{\text { Jumlah kelas }}=\frac{99-64}{5}=7$ 
Tabel 1. Pengalaman responden dalam mengonsumsi makanan khas Bogor

\begin{tabular}{ccc}
\hline Nama & $\begin{array}{c}\text { Pernah } \\
\text { (orang) }\end{array}$ & $\begin{array}{c}\text { Tidak pernah } \\
\text { (orang) }\end{array}$ \\
\hline Roti Unyil & 99 & 1 \\
Lapis Talas & 99 & 1 \\
Soto Mie & 98 & 2 \\
Asinan & 96 & 4 \\
Soto Kuning & 93 & 7 \\
Tauge goring & 87 & 13 \\
Laksa & 77 & 23 \\
Talas Kukus & 75 & 25 \\
Doclang & 74 & 26 \\
Makaroni Panggang & 74 & 26 \\
Es Pala & 70 & 30 \\
Cungkring & 64 & 36 \\
\hline
\end{tabular}

(Sumber : Data primer diolah, 2019)

Tabel 2. Hasil pengelompokan popularitas makanan khas Bogor

\begin{tabular}{cclc}
\hline $\begin{array}{c}\text { Jumlah } \\
\text { Skor }\end{array}$ & Kategori & \multicolumn{1}{c}{$\begin{array}{c}\text { Nama makanan } \\
\text { khas }\end{array}$} & $\begin{array}{c}\text { Persentase } \\
(\%)\end{array}$ \\
\hline $93-100$ & $\begin{array}{c}\text { Sangat } \\
\text { populer }\end{array}$ & $\begin{array}{l}\text { Asinan, Lapis } \\
\text { Talas, Roti Unyil, } \\
\text { Soto Kuning, dan } \\
\text { Soto Mie }\end{array}$ & 41,6 \\
& & Tauge Goreng & 8,33 \\
$85-92$ & Populer & 8,33 \\
$77-84$ & $\begin{array}{c}\text { Cukup } \\
\text { populer }\end{array}$ & Laksa \\
$69-76$ & $\begin{array}{c}\text { Tidak } \\
\text { populer }\end{array}$ & $\begin{array}{l}\text { Es Pala, Doclang, } \\
\text { Makaroni } \\
\text { Panggang, dan } \\
\text { Talas Kukus }\end{array}$ & 33,34 \\
& & Cungkring & 8,33 \\
$61-68$ & $\begin{array}{c}\text { Sangat tidak } \\
\text { populer }\end{array}$ & Con \\
\hline
\end{tabular}

Berdasarkan penilaian popularitas pada Tabel 2, diketahui bahwa nilai popularitas berkisar antara 64 - 99. Makanan khas yang sangat populer meliputi Asinan, Lapis Talas, Roti Unyil, Soto Kuning, Soto Mie, dan Tauge Goreng. Makanan khas yang populer yaitu Tauge Goreng. Makanan khas yang cukup populer yaitu Laksa. Makanan khas tidak populer meliputi Es Pala, Doclang, Makaroni Panggang, dan Talas Kukus Sedangkan makanan khas yang sangat tidak populer yaitu Cungkring. Produk inilah yang diprioritaskan untuk dianalisis lebih lanjut berdasarkan tingkat kepuasan dan kepentingan konsumen supaya dapat diketahui atributatribut yang perlu diperbaiki.

Cungkring adalah makanan berupa potongan kiki sapi yang dimasak menggunakan kunyit, kemudian disantap bersama lontong dan disiram dengan saus kacang seperti bumbu sate. Pada umumnya penjual Cungkring menyiapkan makanan tambahan seperti tempe goreng dan oncom goreng tepung. Harga 1 porsi Cungkring pada tahun 2019 yaitu Rp 6.000,00 dengan isi 2 potong kikil dan 1 buah lontong. Cungkring disajikan dalam daun pisang yang dilapisi kertas nasi dan disediakan lidi sebagai penusuk untuk mempermudah konsumen dalam memakan kikil. Pada umumnya penjual Cungkring menjual dagangannya menggunakan gerobak yang dipikul dan menetap di Jalan Surya Kencana Bogor. Gerobak dagangan yang digunakan yaitu kotak kayu berdinding kaca. Konsumen tidak mengonsumsi cungkring di lokasi penjualan namun membungkusnya untuk dibawa pulang. Cungkring dapat dibeli pada pukul 08.00 sampai dengan 11.00 di Jalan Surya Kencana Bogor.

\section{Tingkat Kepuasan dan Kepentingan Konsumen}

Tingkat kepentingan dan kepuasan konsumen terhadap 18 atribut Cungkring ditampilkan pada Tabel 3. Hasil kuesioner memperlihatkan bahwa tingkat kepuasan kepuasan konsumen berkisar dari 3,19 (netral) - 4,79 (puas) sedangkan tingkat kepentingan berkisar dari 3,25 (netral) - 4,19 (penting).

\section{Posisi Atribut pada Kuadran}

Perhitungan titik potong $\mathrm{X}$ dan $\mathrm{Y}$ dapat dilihat pada Persamaan 4 dan 5.

$\overline{\bar{x}}_{i}=\frac{\text { Total rata-rata kepuasan }}{\text { Jumlah atribut }}$

$\overline{\bar{x}}_{i}=\frac{72,89}{18}=4,05$

$\overline{\bar{y}}_{i}=\frac{\text { Total rata-rata kepentingan }}{\text { Jumlah atribut }}$

$\overline{\bar{y}}_{i}=\frac{67,56}{18}=3,75$

Berdasarkan perhitungan dengan menggunakan Persamaan 4 dan 5, diperoleh Matrix Importance Performance seperti yang dapat dilihat pada Gambar 
Tabel 3 . Tingkat kepuasan dan kepentingan konsumen pada produk Cungkring

\begin{tabular}{|c|c|c|c|c|c|}
\hline No & Nama atribut & $\begin{array}{c}\text { Skor } \\
\text { kepuasan }\end{array}$ & $\begin{array}{c}\text { Rerata } \\
\text { kepuasan }(X)\end{array}$ & $\begin{array}{c}\text { Skor } \\
\text { kepentingan }\end{array}$ & $\begin{array}{c}\text { Rerata } \\
\text { kepentingan }(\mathrm{Y})\end{array}$ \\
\hline 1 & Rasa bumbu & 479 & 4,79 & 419 & 4,19 \\
\hline 2 & Higienitas & 474 & 4,74 & 403 & 4,03 \\
\hline 3 & Lokasi bersih & 458 & 4,58 & 396 & 3,96 \\
\hline 4 & Tekstur cungkring & 449 & 4,49 & 396 & 3,96 \\
\hline 5 & $\begin{array}{l}\text { Aroma/wangi khas } \\
\text { cungkring }\end{array}$ & 436 & 4,36 & 394 & 3,94 \\
\hline 6 & Harga terjangkau & 414 & 4,14 & 393 & 3,93 \\
\hline 7 & Porsi cungkring & 411 & 4,11 & 387 & 3,87 \\
\hline 8 & Harga sesuai porsi & 411 & 4,11 & 384 & 3,84 \\
\hline 9 & $\begin{array}{l}\text { Lokasi mudah } \\
\text { dijangkau }\end{array}$ & 406 & 4,06 & 383 & 3,83 \\
\hline 10 & $\begin{array}{l}\text { Warna bumbu } \\
\text { cungkring }\end{array}$ & 403 & 4,03 & 379 & 3,79 \\
\hline 11 & $\begin{array}{l}\text { Kemasan yang } \\
\text { digunakan }\end{array}$ & 398 & 3,98 & 379 & 3,79 \\
\hline 12 & Warna kikil & 393 & 3,93 & 376 & 3,76 \\
\hline 13 & Fasilitas tempat duduk & 389 & 3,89 & 367 & 3,67 \\
\hline 14 & Kecepatan penyajian & 387 & 3,87 & 358 & 3,58 \\
\hline 15 & $\begin{array}{l}\text { Promosi melalui media } \\
\text { sosial }\end{array}$ & 372 & 3,72 & 351 & 3,51 \\
\hline 16 & $\begin{array}{l}\text { Promosi melalui } \\
\text { pameran }\end{array}$ & 354 & 3,54 & 335 & 3,35 \\
\hline 17 & $\begin{array}{l}\text { Promosi melalui acara } \\
\text { demo masak }\end{array}$ & 336 & 3,36 & 331 & 3,31 \\
\hline \multirow[t]{2}{*}{18} & $\begin{array}{l}\text { Promosi melalui acara } \\
\text { TV }\end{array}$ & 319 & 3,19 & 325 & 3,25 \\
\hline & Total & & 72,89 & & 67,56 \\
\hline
\end{tabular}

(Sumber: Data primer diolah, 2019)

1. Adapun keterangan mengenai posisi masing-masing atribut dapat dilihat pada Tabel 4.

Atribut yang berada pada kuadran I merupakan atribut dengan tingkat kepentingan yang tinggi (sumbu y sebelah atas) namun tingkat kepuasan yang rendah (sumbu x sebelah kiri). Atribut tersebut mencakup warna bumbu Cungkring, warna kikil, kemasan yang digunakan dan kecepatan pada saat penyajian Cungkring. Atributatribut inilah yang menjadi prioritas untuk diperbaiki. Perbaikan terhadap atribut produk Cungkring sebagai makanan khas yang sangat tidak populer diharapkan dapat meningkatkan kepuasan konsumen sekaligus juga meningkatkan popularitas Cungkring sehingga dapat dikenal lebih luas oleh masyarakat.

\section{Upaya Perbaikan Warna Bumbu Cungkring}

Cungkring merupakan makanan yang berbahan dasar kikil yang ditambahkan bumbu kacang. Warna bumbu Cungkring yaitu coklat sedikit kuning hampir sama seperti bumbu sate, namun bumbu Cungkring sedikit lebih pucat dan terlihat tidak menarik. Menurut Wonggo (2010) warna merupakan salah satu indikator dalam penentuan kualitas bahan, karena dapat diidentifikasi oleh panca indera terlebih dahulu. Bahan pangan yang berwarna kurang sedap dipandang atau menyimpang dari warna semestinya, meskipun memiliki rasa enak dan tekstur yang baik, menjadikannya tidak layak dikonsumsi. 


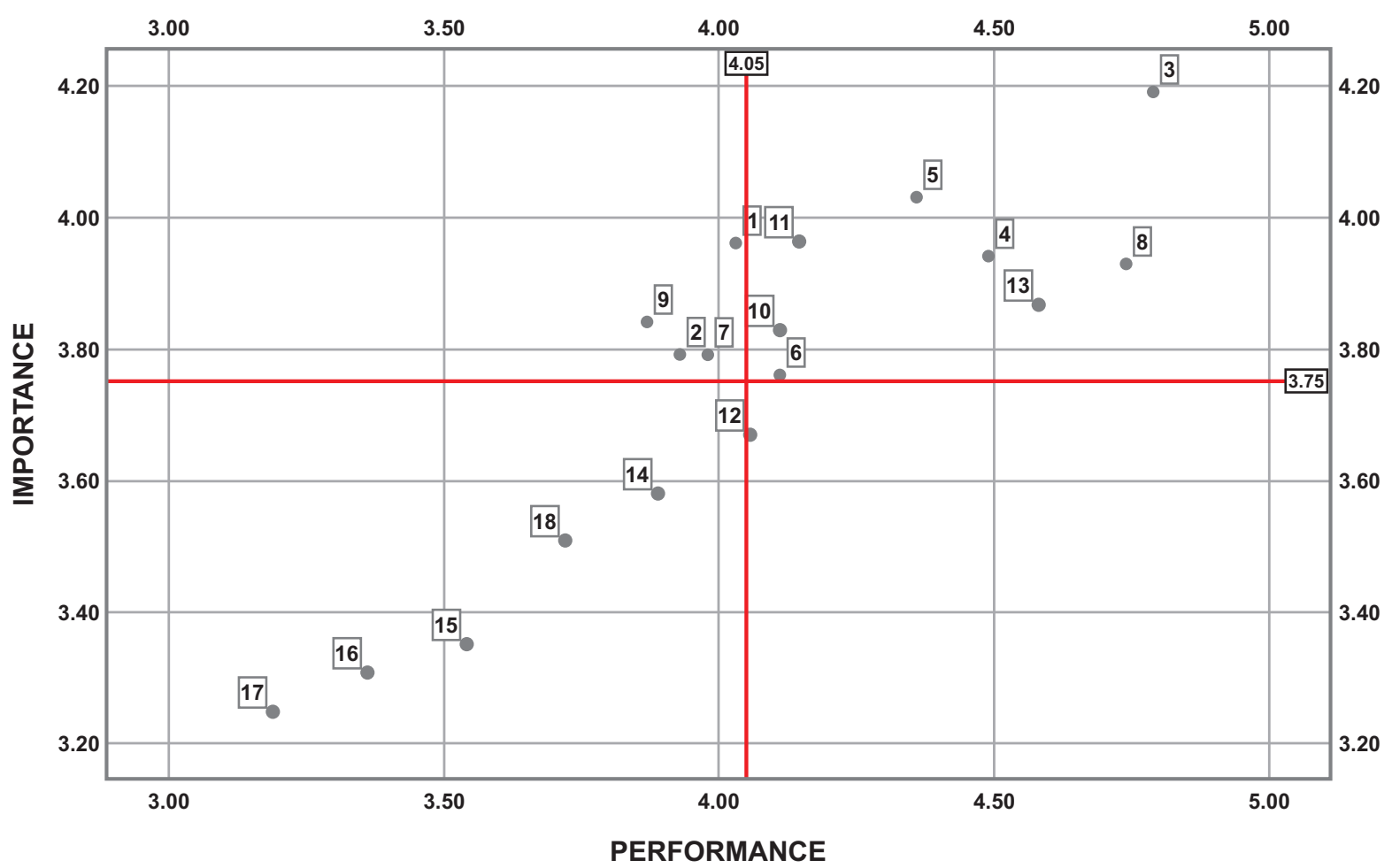

Gambar 1. Matrix importance performance dari produk Cungkring

Bumbu Cungkring terbuat dari bawang merah, cabai merah dan cabai rawit yang dihaluskan kemudian ditumis. Setelah itu ditambahkan kacang tanah yang sudah digoreng dan ditumbuk, diaduk sampai rata sambil ditambahkan air hingga kental baru kemudian ditambahkan garam dan kecap manis. Selama ini penjual tidak menambahkan kecap pada saat mengemas Cungkring, sehingga warna bumbu terlihat pucat dan kurang menarik. Oleh sebab itu perlu dilakukan penambahan kecap kembali pada bumbu Cungkring. Tentu saja penambahan kecap perlu dilakukan dengan hati-hati dan cermat, agar tidak menimbulkan rasa dan warna yang kurang diinginkan seperti rasa menjadi terlalu manis atau warna terlalu gelap.

Alternatif lain untuk memperbaiki warna bumbu adalah dengan mengganti proses penggorengan dengan penyangraian. Penyangraian merupakan proses penggorengan tanpa penggunaan minyak. Menurut Siswantoro dkk. (2014), penyangraian akan memberikan warna yang lebih pekat dan kandungan lemak dalam produk lebih rendah, sehingga produk tidak mudah tengik. Hal ini juga dapat menghemat penggunaan minyak goreng yang berdampak pada pengurangan biaya produksi.

Selanjutnya yang dapat dilakukan untuk memperbaiki warna bumbu Cungkring yaitu dengan penambahan cabai merah. Warna merah pada cabai akan membuat warna bumbu yang terlihat pucat menjadi lebih cerah dan menarik. Menurut Saadah dkk. (2016), warna merah dari cabai disebabkan karena adanya senyawa $\beta$-karoten yang merupakan suatu kelompok pigmen yang memberikan oranye atau merah pada buah dan sayuran. Cabai merah yang akan digunakan untuk membuat bumbu sebaiknya dilakukan proses blanching terlebih dahulu agar warna yang dihasilkan lebih baik dan tidak kecoklatan (browning). Proses blanching pada sayuran berfungsi untuk menginaktivasi enzim penyebab browning atau pencoklatan. Pada proses blanching terjadi inaktivasi enzim penyebab browning, pelunakan jaringan dan penghilangan bau dan flavor yang tidak dikehendaki, sehingga memudahkan proses selanjutnya (Tunde-Akintunde, 2010).

\section{Upaya Perbaikan Warna Kikil}

Atribut lain yang perlu diperbaiki dari produk Cungkring adalah warna kikil. Kikil merupakan bahan yang ditambahkan selain lontong yang terbuat dari beras. Kikil pada Cungkring berwarna kuning pucat. Penjual Cungkring mengolah kikil dengan cara perebusan untuk perontokkan rambut-rambut yang terdapat pada kikil, pengempukan, dan penghilangan bau amis. Pada perebusan sebaiknya dilakukan penambahan kunyit untuk memberikan warna yang 
Tabel 4. Kuadran dan atribut produk cungkring

\begin{tabular}{|c|c|}
\hline Kuadran & Atribut \\
\hline $\begin{array}{l}\text { I (Prioritas utama) } \\
\text { Kuadran } 1 \text { terletak pada bagian kiri atas (tingkat } \\
\text { kepuasan/performance rendah, tingkat kepentingan/ } \\
\text { importance tinggi). Atribut yang berada pada kuadran ini } \\
\text { harus diprioritaskan untuk mendapat perbaikan. }\end{array}$ & $\begin{array}{l}\text { 1. Warna bumbu Cungkring } \\
\text { 2. Warna kikil } \\
\text { 7. Kemasan yang digunakan pada penyajian Cungkring } \\
\text { 9. Kecepatan pada saat penyajian Cungkring }\end{array}$ \\
\hline $\begin{array}{l}\text { II (Pertahankan prestasi) } \\
\text { Kuadran } 2 \text { terletak pada bagian kanan atas (tingkat } \\
\text { kepuasan/performance tinggi, tingkat kepentingan/ } \\
\text { importance tinggi). Atribut pada kuadran ini adalah } \\
\text { atribut yang harus dipertahankan kinerjanya. }\end{array}$ & $\begin{array}{l}\text { 3. Rasa bumbu Cungkring } \\
\text { 4. Tekstur Cungkring } \\
\text { 5. Aroma/wangi khas Cungkring } \\
\text { 6. Porsi Cungkring yang diberikan } \\
\text { 8. Higienitas saat penyajian Cungkring } \\
\text { 10. Harga Cungkring sesuai porsi } \\
\text { 11. Harga Cungkring terjangkau } \\
\text { 13. Lokasi penjualan Cungkring bersih }\end{array}$ \\
\hline $\begin{array}{l}\text { III (Prioritas rendah) } \\
\text { Kuadran } 3 \text { terletak pada bagian kiri bawah (tingkat } \\
\text { kepuasan/performance rendah, tingkat kepentingan/ } \\
\text { importance rendah). Atribut pada kuadran ini belum } \\
\text { mendesak untuk diperbaiki. }\end{array}$ & $\begin{array}{l}\text { 14. Fasilitas tempat duduk } \\
\text { 15. Promosi melalui pameran } \\
\text { 16. Promosi melalui demo masak } \\
\text { 17. Promosi melalui acara TV } \\
\text { 18. Promosi melalui media sosial (instagram, facebook, } \\
\text { dsb). }\end{array}$ \\
\hline $\begin{array}{l}\text { IV (Berlebihan) } \\
\text { Kuadran } 4 \text { terletak pada bagian kanan bawah (tingkat } \\
\text { kepuasan/performance tinggi, tingkat kepentingan/ } \\
\text { importance rendah) Atribut pada kuadran ini tidak perlu } \\
\text { ditingkatkan kinerjanya untuk efisiensi biaya. }\end{array}$ & 12. Lokasi penjualan Cungkring mudah dijangkau \\
\hline
\end{tabular}

lebih baik pada kikil. Penambahan kunyit ini perlu diatur waktu dan jumlahnya. Pemberian kunyit sebanyak $35 \%$ selain akan memberikan warna yang lebih cerah juga memberikan efek yang positif yaitu menghambat pertumbuhan mikroba (Purwani dkk., 2012).

\section{Upaya Perbaikan Kemasan}

Cungkring terdiri dari kikil, ketupat, dan bumbu kacang, yang dikemas secara bersamaan dalam kertas nasi (kertas berlapis plastik tipis) dan dialasi dengan selembar daun pisang. Kemasan kertas memiliki sifat yang fleksibel, namun kemasan kertas tidak dapat digunakan untuk mengemas produk cair dan tidak dapat dipanaskan. Selain itu kertas memiliki sifat yang sensitif terhadap air dan mudah dipengaruhi oleh kelembaban udara (Robertson, 2016). Penggunaan kertas untuk mengemas produk Cungkring yang mengandung bumbu kacang yang cair menyebabkan bahan yang dikemas mudah mengalami kebocoran dan kontak dengan udara. Apalagi bumbu Cungkring, adalah bahan pangan yang berlemak tinggi $(42,7 \mathrm{~g} / 100$ g) karena bahan utamanya berasal dari kacang tanah yang digoreng. Bumbu yang kontak dengan udara akan mudah mengalami ketengikan (Indraswasti, 2017) akibat oksidasi lemak (Darawati dan Pranoto, 2010).
Kemasan lain yang digunakan pada produk Cungkring yaitu daun. Menurut Harijati dkk. (2013), daun pisang merupakan pembungkus alami yang tidak mengandung bahan kimia, murah, mudah ditemukan, mudah dilipat dan tidak mengubah warna makanan. Namun demikian, pemakaian daun pisang memiliki kekurangan, antara lain mudah sobek dan kebersihannya kurang terjamin apabila sebelum digunakan hanya di lap pada permukaannya saja.

Kemasan kertas nasi dan daun pisang kurang cocok untuk mengemas Cungkring terutama bumbu kacangnya. Bumbu kacang ini sebaiknya dikemasterpisah (tidak disatukan dengan lontong dan kikil) dengan menggunakan kemasan yang sesuai. Hal ini sejalan dengan penelitian Nur (2012), yang menyatakan bahwa penggunaan bahan pengemas harus sesuai dengan sifat bahan yang dikemas. Selain itu untuk meningkatkan popularitas di kalangan masyarakat ataupun wisatawan, perlu diupayakan pemasaran Cungkring yang lebih luas dengan menjadikannya sebagai oleh-oleh khas Bogor. Salah satunya dengan mengolah produk Cungkring yang lebih higienis dengan mengemas bumbu dengan botol kaca. Penelitian Amanda (2019) menunjukkan bahwa umur simpan bumbu pliek u (bumbu dari hasil fermentasi alami daging buah kelapa khas Aceh) yang 
dikemas dengan botol kaca memiliki umur simpan yang lebih lama dibandingkan dengan pliek u yang dikemas dengan pouch plastik dan pouch alufo. Hasil yang senada diperoleh Afdillah dkk. (2018) yang melakukan penelitian penggunaan botol kaca pada untuk mengemas abon ikan tongkol. Pengemasan dengan botol kaca memberikan umur simpan abon ikan yang lebih panjang daripada pengemasan menggunakan Alumunium Foil.

Penggunaan botol kaca merupakan pilihan yang baik dalam mengemas bahan pangan yang mengandung lemak. Hal ini karena lemak tidak teroksidasi oleh udara. Selain itu apabila bahan pangan dikemas menggunakan kemasan botol kaca pada suhu dingin maupun suhu kamar, dapat mencegah masuknya air dari udara yang akan menyebabkan hidrolisis (Kusuma dan Kusnadi, 2016). Oleh sebab itu, penggunaan botol kaca berpotensi efektif dalam memperpanjang shelf life dari bumbu Cungkring.

Selain menggunakan botol kaca untuk bumbu kacang, bahan lainnya seperti kikil dan ketupat dapat dikemas dalam kemasan plastik food grade. Kemasan ini umumnya ditandai dengan adanya simbol gelas dan garpu, yang artinya kemasan tersebut aman untuk makanan dan minuman (Robertson, 2016). Jenis plastik yang relatif aman digunakan sebagai kemasan pangan adalah PP (Polipropilen). Salah satu kemasan yang cocok untuk Cungkring adalah plastik polipropilen. Bahan kemasan plastik ini cocok untuk mengemas Cungkring yang terdiri dari kikil dan bumbu kacang untuk menghindari kebocoran dan resiko ketengikan yang lebih cepat dari produk Cungkring khususnya bumbu kacangnya.

Hasil penelitian Irawati (2014) menunjukkan bahwa penggunaan PP (Polipropilen) pada pengemasan daging ayam memberikan angka kuman yang lebih sedikit dibandingkan dengan pengemas plastik lainnya. Kemasan jenis PP selain memiliki keunggulan harga yang murah, mudah dibentuk, tidak korosif, praktis, juga memiliki permeabilitas terhadap oksigen dan daya tembus uap air yang rendah. Penggunaan plastik PP untuk mengemas kikil dan ketupat merupakan pilihan yang tepat karena dapat meminimalkan kontak bahan dengan mikroorganisma sehingga shelf life produk Cungkring dapat lebih panjang dibandingkan dengan dikemas dengan kertas nasi.

\section{Upaya Perbaikan Kecepatan Penyajian Cungkring}

Kecepatan penyajian merupakan atribut yang perlu diperbaiki juga karena ternyata pada penyajian Cungkring dibutuhkan waktu yang relatif lama yaitu berkisar antara 4-6 menit untuk 1 porsi. Apabila ratarata 1 orang konsumen memesan Cungkring sebanyak 3 porsi maka akan membutuhkan waktu 12 menit untuk menyelesaikan pesanannya. Waktu tunggu konsumen akan menjadi lebih panjang apabila banyak konsumen lain yang mengantri. Selain itu, panasnya suhu udara di pinggir jalan tempat gerobak Cungkring ini berada, menambah ketidaknyamanan konsumen ketika membeli Cungkring. Menurut Hardyasar dkk. (2017) dan Novrianto (2016), kecepatan dalam menyajikan produk yang dipesan merupakan faktor penting yang harus diperhatikan. Penyajian makanan yang lama dapat membuat konsumen merasa kurang nyaman dan tidak puas.

Upaya yang dapat dilakukan untuk mempercepat waktu penyajian adalah dengan memangkas waktu persiapan makanan. Pada produk Cungkring, upaya mempersingkat waktu penyajian dapat dilakukan dengan mempersiapkan terlebih dahulu bahan-bahan, misalnya dengan telah menyiapkan kikil dalam bentuk potongan-potongan dan mengemas bumbu dalam kemasan plastik.

\section{KESIMPULAN}

Terdapat 12 makanan khas bogor yaitu Soto Mie, Soto Kuning, Laksa, Asinan, Doclang, Cungkring, Es Pala, Lapis Talas, Talas Kukus, Roti Unyil, Makaroni Panggang, dan Tauge Goreng. Makanan khas yang sangat populer memiliki persentase sebesar $41,67 \%$ (nilai popularitas 93-100) meliputi Asinan, Lapis Talas, Roti Unyil, Soto Kuning, Soto Mie, dan Tauge Goreng. Sedangkan makanan khas yang sangat tidak populer memiliki persentase sebesar $8,33 \%$ (nilai popularitas 61-88) yaitu Cungkring. Strategi perbaikan pada produk Cungkring meliputi perbaikan pada warna bumbu, warna kikil, kemasan, dan kecepatan penyajian.

\section{KONFLIK KEPENTINGAN}

Pada penelitian ini tidak ada konfilik kepentingan dengan pihak manapun.

\section{DAFTAR PUSTAKA}

Afdillah, W., Sulaiman, I., \& Martunis, M. (2018). Pengaruh Kemasan Aluminium Foil dan Botol Kaca terhadap Umur Simpan Abon Ikan Tongkol (Euthynnus affinis) dengan Pendekatan Metode Arrhenius. Jurnal IImiah Mahasiswa Pertanian, 3(3), 185-193.

Amanda, V. (2019). Pendugaan Masa Simpan Bumbu Khas Aceh (Pliek U) dengan Menggunakan Variasi Kemasan. (Thesis), Universitas Syah Kuala.

Darawati, M., \& Pranoto, Y. (2010). Penyalutan kacang rendah lemak menggunakan selulosa eter dengan pencelupan untuk mengurangi penyerapan minyak selama 
penggorengan dan meningkatkan stabilitas oksidatif selama penyimpanan [ether cellulose coatings by dipping on partially defatted peanuts. Jurnal Teknologi dan Industri Pangan, 21(2), 108-116.

Gunawan, T. (2016). Identifikasi Wisata Kuliner Kota Bogor. Jurnal Online Mahasiswa (JOM) Bidang Perencanaan Wilayah \& Kota, 1(1)

Hardyasar, A., Mandei, J. R., \& Dumais, J. N. (2017). Tingkat kepuasan konsumen restoran pondok hijau kota manado. Agri-sosioekonomi, 13(2A), 157-172.

Harijati, N., Azrianingsih, R., \& Prawaningtyas, E. A. (2013). The Study of Anatomy and Fiber Banana Leaf as a Potensial Wrapping.

Indraswasti, D. (2017). Ponorogo: Forum Ilmiah Kesehatan (FORIKES).

Irawati, N. (2014). Penggunaan kemasan plastik jenis PE (polythylen), PP (polypropylen) dan plastik wrap terhadap angka kuman pada daging ayam. VISIKES: Jurnal Kesehatan Masyarakat, 13(1).

Knotts, T. L., Jones, S. C., \& Udell, G. G. (2009). Innovation Evaluation And Product Marketability. The Marketing Management Journal, 19(2), 84-90.

Kominfo. (2017). Jumlah Wisatawan 2017 Diprediksi Naik.

Kusuma, T. S., \& Kusnadi, J. (2016). Asam lemak bebas dan bilangan asam selai kacang "home fortification" selama penyimpanan (free fatty acids and acid values of" home fortification" peanut butter during storage). Indonesian Journal of Human Nutrition, 3(2), 84-92.

Levy, P. S., \& Lemeshow, S. (2013). Sampling of populations: methods and applications: John Wiley \& Sons.

Melfa, Y., \& Duwi, B. (2013). Analisis kepuasan konsumen terhadap kualitas pelayanan dan harga produk pada supermarket dengan menggunakan metode Importance Performance Analysis (IPA). Jurnal Optimasi Sistem Industri, 12(12), 301-309.

Mulyana, B. (2012). Pengembangan Kota Bogor Sebagai Destinasi Pariwisata Internasional. Jurnal Ilmiah Pariwisata, 2(1), 109-222.

Mutaqin, A. R., Hardhienata, S., \& Chairunnas, A. (2015). Aplikasi Wisata Kuliner di Kota Bogor Berbasis Android Jurnal Online Mahasiswa (JOM) Bidang Ilmu Komputer/ Informatika, 3(3).

Novrianto, J. (2016). Analisis kepuasan pelanggan pada restoran sop tunjang pertama (m1) di Pekanbaru. Jurnal Valuta, 2(2), 171-189.

Nur, M. (2012). Pengaruh cara pengemasan, jenis bahan pengemas, dan lama penyimpanan terhadap sifat kimia, mikrobiologi, dan organoleptik sate bandeng (Chanos chanos). Jurnal Teknologi \& Industri Hasil Pertanian, 14(1), 1-11.

Nurwitasari, A. (2015). Pengaruh Wisata Gastronomi Makanan Tradisional Sunda terhadap Keputusan Wisatawan Berkunjung ke Kota Bandung. Jurnal Barista, 2(1).

Purwani, E., Retnaningtyas, E., \& Widowati, D. (2012). Pengembangan Model Pengawet Alami Dari Ekstrak Lengkuas (Languas Galanga), Kunyit (Curcuma Domestica) Dan Jahe (Zingiber Officinale) Sebagai Pengganti Formalin Pada Daging Segar (the Nature Preservative From Extract of Languas Galanga, Curcuma Domestic. Paper presented at the Proceeding Biology Education Conference: Biology, Science, Enviromental, and Learning.

Robertson, G. L. (2016). Food packaging: principles and practice: CRC press.

Rusdiana, D. (2016). Sistim Informasi Peta Berbasiskan Web Untuk Wisata Kuliner, Tempat Rekreasi dan Tempat Bersejarah di Kota Bogor. Jurnal Online Mahasiswa (JOM) Bidang Teknik Geodesi, 1(1).

Saadah, M., Nurdiana, N., \& Wahyudiati, D. (2016). Uji kadar zat warna ( $\beta$-karoten) pada cabe merah (capsicum annum. Linn) sebagai pewarna alami. Biota, 9(1), 86-95.

Sanny, L. (2015). Strategi Pengembangan Usaha Toge Goreng di Kota Bogor dengan Konsep Bisnis Bermitra. Prosiding SNaPP: Sosial, Ekonomi dan Humaniora, 5(1), 535-542.

Sari, H. P. R. (2017). Analisis keautentikan dan keunikan laksa cihideung sebagai kuliner unggulan kota bogor. Transparansi: Jurnal Ilmiah Ilmu Administrasi, 9(2), 255-269.

Siswantoro, Ediati, R., \& Lestari, R. (2014). Rancang bangun alat penggoreng tanpa minyak untuk menunjang agroindustri. Jurnal Agroindustri, 18(2), 167-169.

Sugiyono. (2013). Metode Penelitian Pendidikan Pendekatan Kuantitatif, Kualitatif, dan R\&D. Bandung: Alfabeta.

Sunyoto, D. (2014). Konsep Dasar Riset Pemasaran dan Perilaku Konsumen. Yogyakarta: Center for Academic Publishing Service.

Tunde-Akintunde, T. (2010). Effect of pretreatment on drying time and quality of chilli pepper. Journal of Food Processing and Preservation, 34(4), 595-608.

Wonggo, D. (2010). Penerimaan konsumen terhadap selai rumput laut (Kappaphycus alvarezii). Jurnal Perikanan dan Kelautan Tropis, 6(1), 51-53. 